\title{
Active Remote Sensing: Lidar SNR Improvements
}

\author{
Yasser Hassebo \\ LaGuardia Community College of the City University of New York \\ USA
}

\section{Introduction}

RAdio Detection And Ranging (RADAR), SOund NAvigation and Ranging (SONAR), and LIght Detection And Ranging (LIDAR) are active remote sensing systems used for earth observations (Planes and ships' locations and velocity information, air traffic control, oceanographic and land info, ), bathymetric mapping (e.g., hypsometry, Ocean depth (echosounding), SHOALS, and seafloor), and topographic mapping. Integrating laser with RADAR techniques - laser RADAR or LIDAR - after World War II introduces scientists to a new era of Remote Sensing technologies. LIDAR is one of the most widely used active remote sensing systems to attain elevation information which an essential component to obtain geographical data. While RADAR is transmitting a long-wavelength signal (i.e., radio or microwave: $\mathrm{cm}$ scale) to the atmosphere and then collecting the backscattering energy signal, LIDAR transmission is a short-wavelength laser beam(s) (i.e., $\mathrm{nm}$ scale) to the atmosphere and then detecting the backscattering light signal(s). More lidar principles and comparison between active remote sensing techniques are introduced in section 1.1 of this chapter.

\section{Lidar background}

\subsection{Lidar historical background}

After World War II the first LIght Detection And Ranging (lidar) system was invented (Jones 1949). The light source was a flash light between aluminum electrodes with high voltage amplitude transmitter, and the receiver optics were two mirrors. Afterward a photoelectrical cell was used as a detector. During daylight, this system had been used to measure the height of cloud ceiling up to $5.5 \mathrm{~km}$. At that time the acronym lidar didn't exit (Middleton 1953). The real revolution of lidar began with the invention of the laser (light amplification by stimulated emission of radiation) in 1960. Using laser as a source of light in a lidar system is referred to as "Laser Radar, or Ladar, or Lidar". Lidar operates in wide band region of the electromagnetic spectrum; ultraviolet $(225 \mathrm{~nm}-400 \mathrm{~nm})$, visible $(400 \mathrm{~nm}-700$ $\mathrm{nm})$, and infrared radiation (700 nm- $1200 \mathrm{~nm})$. Lidar systems are used as ground based stations (stationary or mobile), or can be carried on platforms such as airplanes or balloons (in-situ operations), or on satellites. National Oceanic and Atmospheric Agency (NOAA) and National Aeronautics and Space Administration (NASA) aircraft and satellites are the most famous lidar platforms in the United States of America. Some other platforms are 
employed around the world by groups such as the European Space Agency (ESA), the Japanese National Institute for Environmental Studies (NIES), and the National Space Development Agency of Japan (NASDA).

\section{What is a lidar}

LIght Detection And Ranging (lidar) is an optical remote sensing system for probing the earth's atmosphere through Laser transmitter using elastic and/or inelastic scattering techniques. Most of the remote sensing lidar systems consist of three functional subsystems, as shown in Figure 1, which vary in the details based on the particular applications. These subsystems are: (1) Transmission subsystem, (2) Receiver subsystem, (3) Electronics subsystem.

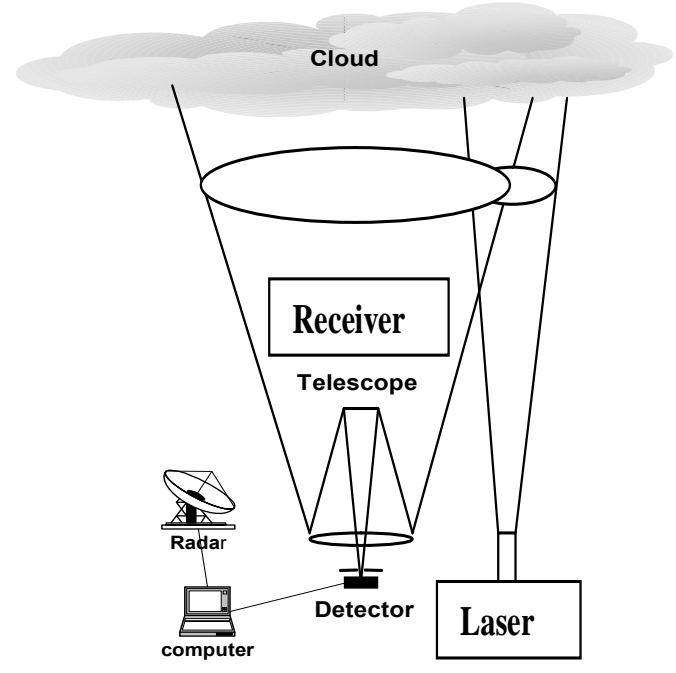

Fig. 1. Essential elements of a lidar system

In the transmission subsystem, a laser (pulsed or continuous wave $(\mathrm{CW})$ ) is used as a light source. More than one laser can be used according to lidar type and objective of the measurements. Laser pulses, in the ideal case, are very short pulses with narrow bandwidth, high repetition rate, very high peak power, and are propagated with a small degree of divergence. The laser pulse is transmitted through transmission optics to the atmospheric object of interest. The essential function of the output optics is to improve the output laser beam properties and/or control the outgoing beam polarization. Elements such as lenses and mirrors are used to improve the beam collimation. Beam expansion is used to reduce the beam divergence and the area density of the laser pulse. Fiber optic cable, filters, and cover shields or housings serve the dual purpose of preventing the receiver detectors from saturation due to any unwanted transmitted radiations and of protecting the user's eyes against any injury. Wave length selective devices are also used, such as harmonic generator, to create the second, the third and the fourth harmonic. Polarizer can be used to control the transmitted beam polarization. Polarization measurement equipments are used as well. The experimental results, in this chapter, had been produced using two types of pulsed laser, Q- 
Switched (an optical on-off switch) Nd: YAG (Continuum Infinity 40-100) and Q-Switched Nd: YAG (Surelite) at CCNY.

A Receiver subsystem consists of an optical telescope to gather and focus the backscattering radiations, and receiver optics to provide the detector (PhotoMultiplier Tube (PMT) or Avalanche Photo Diode (APD)) with desirable collimated or/and focused strong polarized signal. Components such as mirrors, collimated lenses, aperture (field stop), ND (Neutral Density) filters, and Interference Filters (IF) are to provide special filtering against sky background radiations, analyzers (polarization selection components) are needed to select the necessary polarizations based on the applications and/or to discriminate against the unwanted background noise (as shown in chapter 7), and electro-optical elements that convert light energy to electrical energy (detectors). There are two basic types of detectors for lidar systems; the photomultiplier tube (PMT), and the avalanche photo diode (APD). In addition to the optics mounts and the manually operation aids, automated alignment capabilities for lidar long-term unattended operations are needed.

Electronic subsystem consists of data acquisition (mostly, multiple channels), displaying unites, Analog to Digital (A/D) signals conversions, radar and radar circuit, control system especially for our polarization discrimination technique which I presented in this dissertation (Chapter 7) to track the azimuth angles to improve the SNR. In addition, software (Labview and Matlab) is needed for signal processing purposes, as well some hardware such as platforms (van for a ground based mobile lidar, airplane or balloon for insitu airborne lidar and satellite for higher altitude space-based scanning lidar), a temperature control unit, orientation stability elements, storage units and some additional equipment depending on lidar's type and measurement objective.

\subsection{How does lidar work?}

Using the well known fact that the laser energy of optical frequencies is highly monochromatic and coherent, and the revolution of developing the Q-Switching by McClung and Hellwarth on 1962, (McClung 1962), laser has the capability of producing pulses with very short duration, narrow bandwidth, very high peak energy, propagating into the atmosphere with small divergence degree. This prompted the development of backscattering techniques for environment and/or atmosphere compositions and structure, (aerosol, ozone, cloud plumes, smoke plumes, dust, water vapor and greenhouse gases (e.g. carbon dioxide), temperature profile, wind speed, gravity waves, etc.), distributions, concentrations and measurements. These measurement techniques are to some extent analogous to radar, except using light waves as an alternative to radio waves. Consequently, scientists denote lidar as laser radar. The essential idea of lidar operations and measurements is based on the shape of the detected backscattering lidar signals with wavelength of $(\lambda)$ if the transmitted laser beam of wavelength $\left(\lambda_{L}\right)$ is scattering back from distance $R$. This backscattering shape depends on the properties of the lidar characteristics and the atmosphere specifications. The transmitted lidar signal can be absorbed, scattered, and shifted, or its polarization can be changed by the atmosphere compositions and scattered in all the directions with some signals scattered back to the lidar receiver. Two parameters, in the lidar return equation, relate the lidar detected signal power and the atmospheric specifications. These parameters are the extinction and scattering coefficients, $a$ $(\lambda, R), \beta(\lambda, R)$ respectively. By solving the lidar equation for those coefficients one can 
determine various atmospheric properties. An example of these determination processes, which based on the lidar type and the physical process used in the measurements, have been introduced in this chapter.

\section{Lidar classifications}

Ways to classify lidar systems are: (1) the kind of physical processes (Rayleigh, Mie, elastic and inelastic backscattering, absorption, florescence, etc.), (2) the types of the laser employed (Die, and ND:YAG), (3) the objective of the lidar measurements (aerosols and cloud properties, temperature, ozone, humidity and water vapor, wind and turbulence, etc.), (4) the atmospheric parameters that can lidar measure (atmospheric density, gaseous pollutants, atmospheric temperature profiles), (5) the wavelength that been used in the measurements (ultraviolet (UV), infrared (IR), and visible), (6) the lidar configurations (monostatic, biaxial, coaxial, vertically pointed and scanning lidars and bi-static), (7) the measurement mode (analogue, digital), (8) the platform type (stationary in laboratories, mobiles in vehicles, in situ (balloon and aircraft), and satellite), and (9) number of wavelength (single, and multiple wavelengths). In the following section anticipate brief descriptions of various types of lidar, focusing mainly on those types of our research interest.

\section{Types of lidar returns}

If light is directed towards other directions because of interaction with matter without loss of energy (but losing intensity) the fundamental physical process is called scattering of light. The light scattering occurs at all wavelengths in the electromagnetic spectrum and in all directions. If lidars sense only the scattering radiations in the backward direction (scattering angle $\theta_{\mathrm{s}}=180^{\circ}$ for monostatic vertically pointed lidar), we call them lidar backscattering radiations or signals. In terms of lidar return signals, lidar has been classified into the following types: Rayleigh, Mie, Raman, DIAL, Doppler, and florescence lidars.

\subsection{Rayleigh scattering lidar}

In 1871, Lord Rayleigh discovered a significant physical law of light scattering with a variety of applications. The most famous applications of this discovery are the blue sky and the sky light partial polarization explanations. Rayleigh scattering is elastic (no wavelength shift) scattering from atmospheric molecules (particle radius is much smaller compared with the incident radiation wavelength i.e. $r_{p}<<\lambda$ ): sum of Cabannes (sum of coherent, isotopic, polarized scattering, which approximately $96 \%$ of the scattering) and rotational- Raman $S$ and $\mathrm{S}^{\prime}$ branch scattering which only $4 \%$ of the scattering proceedings. Based on the Rayleigh-Jeans law, [the Planck radiance is linearly proportional to the temperature, $B(T) \approx\left(2 \kappa_{\mathbf{B}} v^{2} / c^{2}\right)(T)$, where $B(T)$ is the Planck function, $\kappa_{\mathbf{B}}$ is the Boltzmann constant $\kappa_{\mathbf{B}}=103806 \times 10^{-16} \mathrm{erg} \mathrm{deg}^{-1}$, $v$ is the oscillator frequency, $c$ the speed of light, and $T$ the absolute temperature] (Liou 2002), Rayleigh lidar technique can be used to derive the atmospheric temperature profile above the aerosol free region $(R>30 \mathrm{~km})$. Since molecular scattering (Rayleigh scattering or aerosol-free scattering) is proportional to the atmospheric density, the atmospheric temperature profile can be simply derived from the atmospheric density in the range above the aerosol layers (above $30 \mathrm{~km}$ to below $80 \mathrm{~km}$ ). Unfortunately, above $80 \mathrm{~km}$ temperature measurements require a powerful transmitter laser (up to $20 \mathrm{~W}$ ) and receiver telescope (up to $4 \mathrm{~m}$ aperture) which are 
difficult for mobile or airborne platforms (Fhjii and Fukuchi 2005). Finally, assuming the atmosphere consists of molecules only and outside the gaseous absorption bands of the atmosphere, the atmosphere optical thickness can be approximated by

$$
\tau_{m}=0.008569 \lambda^{-4}\left(1+0.0113 \lambda^{-2}+0.00013 \lambda^{-4}\right), \text { where } \lambda \text { is measured in micrometers. }
$$

Rayleigh scattering strongly depends on the wavelength of the transmitted light $(\lambda-4)$ which explains the blue color of the sky, where the scattering efficiency is proportional to $\lambda^{-4}$, i.e. rapid increase in the scattering efficiency with decreasing $\lambda$. This behavior leads to more scatter in blue than red light of the air molecules.

\subsection{Mie backscatter lidars}

For particle radius $\left(r_{p}\right)$ larger than $\lambda / 2 \pi$, (i.e., $r_{p}>\lambda / 2 \pi$, where $\lambda$ is wavelength of radiation ), Rayleigh scattering is not applicable but Mie scattering applies (Mie 1908; Measures 1984; Liou 2002). Mie scattering is elastic scattering which is suitable for detection of large spherical and non-spherical aerosol and cloud particles mainly in the troposphere (Barber 1975), (Wiscombe 1980). The backscattering signals from aerosol or molecules and the absorption from molecules are very strong in the lower part of the atmosphere (below 30 $\mathrm{km}$ ), which is enough to determine various properties about the atmosphere. Micrometersized aerosol and clouds are great indicators of atmosphere boundary phenomena where they show strong backscattering interaction. By Mie scattering theory, the optical properties of water droplets can be evaluated for any wavelength in the electromagnetic spectrum (from solar to microwave) (Deirmendjian 1969). Clouds covered about 50\% of the earth (Liou 2002). Clouds also have an important impact on the global warming disaster when clouds trap the outgoing terrestrial radiation and produce a greenhouse gaseous effect. Mie backscattering lidar measures backscattered radiation from aerosol and cloud particles and their polarization as well (Mie 1908; Liou 2002). Its performance is similar to radar manner. A laser pulse of energy is transmitted, interacted with different objects and then backscattered (scattering angle $=180^{\circ}$ ) to the receiver detector. The detected backscattering signals are interrelated with some properties of that object (even with low concentrations or small change in concentrations of dust or aerosol objects). Mie scattering follows $\left(\lambda^{-0}\right.$ to $\left.\lambda^{-2}\right)$, i.e., it is not significantly dependent on the wavelength.

\subsection{Raman (inelastic backscattering) lidars}

Raman scattering is inelastic scattering with cross section up to three times smaller than the Rayleigh cross section in magnitude. A Raman scattered signal is shifted in frequency from the incident light (Raman-shifted frequency). The Raman scattering coefficient is proportional to the atmospheric density when the air molecule (nitrogen or oxygen) is used as Raman materials (Fhjii and Fukuchi 2005). Generally speaking, Raman lidar measure intensity at shifted wavelength (Stephens 1994) and it detects selected species by monitoring the wavelength-shifted molecular return produced by vibration Raman scattering from the chosen molecules. Raman lidar, originally, was developed for NASA Tropical Ozone Transport Experiment/ Vortex Ozone Transport Experiment (TOTE/VOTE) for methane $\left(\mathrm{CH}_{4}\right)$ and Ozone measurements (Heaps 1996). Also it has been used to correct the microwave temperature profile in the stratosphere (Heaps 1997).Typically; inelastic scattering (such as Raman) is very weak; therefore the daytime measurement is difficult due to the strong 
background solar radiation. This restricts Raman lidar measurements to nighttime use where background solar radiation is absent. On the other hand, Raman lidar is a powerful remote sensing tool used to measure and trace constituents where elastic lidar can not identify the gas species (Fhjii and Fukuchi 2005). Raman-Mie Lidar technique is also used to determine the extinction and the backscattering coefficients assuming the knowledge of air pressure (Ansmann 1992). In this chapter I introduced, a polarization technique to improve lidar Signalto-Noise Ratio (SNR) by reducing the background noise during the daytime measurements. This will help for successful diurnal operation of Raman lidar.

\subsection{DIfferential absorption lidar (DIAL)}

Differential Absorption and Scattering (DAS) is a good combination for detecting a good resolution of water vapor in the atmosphere using the $\mathrm{H}_{2} \mathrm{O}$ absorption line at $690 \mathrm{~nm}$ (Schotland 1966; Measures 1984). DAS technique is one of the best methods for detecting constituents for long-range monitoring based on a comparison between the atmospheric backscattering signals from two adjacent wavelengths that are absorbed differently by the gas of interest (Measures. R. M. 1972). The closest wavelength, of the two adjacent wavelengths, to the absorption line of the molecule of interest (i.e., strongly absorbing spectral location due to the presence of an absorbing gas) is usually called on-line and denoted as $\left(\lambda_{O N}\right)$ and the other laser wavelength is called off-line and denoted as $\left(\lambda_{O F F}\right)$. DIfferential Absorption Lidar (DIAL) technique is a unique method to measure and trace gaseous concentrations in the Planetry Boundary Layer (Welton, Campble et al.) (Welton, Campble et al.) in three dimensional mode (3D) using of the DAS principal. The gas number density $N_{x}(R)$ can be derived from the differential absorption cross section of the molecular species of interest $\left(\Delta \sigma=\sigma\left(\lambda_{\mathrm{ON}}\right)-\sigma\left(\lambda_{\mathrm{OFF}}\right)\right)$ in the DIAL equation (Fhjii and Fukuchi 2005)

$$
N_{x}(R)=\frac{1}{2 \Delta \sigma} \frac{d}{d R} \ln \frac{P\left(R, \lambda_{\text {OFF }}\right)}{P\left(R, \lambda_{\text {ON }}\right)}
$$

Where $P\left(R, \lambda_{\mathrm{ON}}\right)$ and $P\left(R, \lambda_{\mathrm{OFF}}\right)$ the power backscattered signal received from distance $R$ for both wavelengths. Special careful must be taken into account when selecting the adjacent wavelengths, where the different between the two wavelengths is preferred to be $\left\langle 1 \mathrm{~cm}^{-1}\right.$, otherwise another two terms must be considered in the DIAL equation. DIAL, as a range resolved remote sensing technique, can detect lots of pollutants and greenhouse gases $\left(\mathrm{H}_{2} \mathrm{O}\right.$, $\mathrm{SO}_{2}, \mathrm{O}_{3}, \mathrm{CO}, \mathrm{CO}_{2}, \mathrm{NO}, \mathrm{NO}_{2}, \mathrm{CH}_{4}$, etc.) which play a big role in climate change and the earth's radiative budget. DIAL is possible in the UV (200 to $450 \mathrm{~nm}$ ), the visible, and the near IR ( 1 to 5 micrometer), and in the mid-IR (5 to 11 micrometer). For example to measure Ozone as a green house gas with fatal direct effect on human health particularly in the troposphere, DIAL can be used in two appropriate bands; UV band (at $256 \mathrm{~nm}$ ) and the midIR band (960 to $1070 \mathrm{~cm}^{-1}$ ). DIAL operations advantages are successful both day and night, detecting gases and aerosol profiles simultaneously. It can be operated in ground, airborne, and space based platforms.

\subsection{Doppler lidars}

Atmospheric laser Doppler velocimetry including measurements of tornados, storms, wind, turbulence, global wind cycles, and the atmosphere temperature are some of the most important remote sensing techniques (Measures 1984). Doppler broadening is due to the 
Doppler shift associated with the thermal motion of radiating (absorbing) species in the mesopause region such as $\mathrm{Na}, \mathrm{K}, \mathrm{Li}, \mathrm{Ca}$, and Fe (Measures 1984). Furthermore, the atmospheric temperature can be detected by measuring the Doppler broadening and the measured global wind pattern can be determined by measuring the Doppler shift of laserinduced florescence from atmospheric metals atoms such as $\mathrm{Na}$ in the middle and upper atmosphere (Bills 1991; She and Yu 1994). The use of Doppler broadening of the structure of $\mathrm{Na} \mathrm{D}_{2}$ line (by narrowband lidar) technique to determine the range resolved high resolution temperature profile of the mesopause region $(75-115 \mathrm{~km}$, is also called MLT for Mesosphere and Lower Thermosphere) and was proposed by Gibson et al. in 1979. The principle idea is that the absorption line will be broadened because of the Doppler effect for a single $\mathrm{Na}$ atom. Doppler broadened line is given by $\sigma_{D}=\sqrt{\frac{\kappa_{B} T}{M \lambda_{0}^{2}}}$, where $M$ is the mass of a single $\mathrm{Na}$ atom, $\kappa_{B}$ is the Boltzmann constant, $\lambda_{0}$ is the mean $\mathrm{Na} \mathrm{D}_{2}$ transition wavelength, and $T$ is the temperature. As shown the Doppler broadened $\sigma_{D}$ is a function of temperature. Therefore if we measure $\sigma_{D}$ line-width, we can derive the temperature of the $\mathrm{Na}$ atoms in the mesopause which equal to the surrounding atmosphere temperature where $\mathrm{Na}$ atom is in equilibrium condition in the mesopause region (Fhjii and Fukuchi 2005).

\subsection{Resonance fluorescence lidars}

A Rayleigh lidar signal is useless above $\sim 85 \mathrm{~km}$, because of the low atmospheric density above that altitude. The backscattering cross section of Resonance fluorescence lidars is about $10^{14}$ times higher than Rayleigh backscattering cross-section for the same transmitter and receiver specifications, thus Resonance fluorescence lidars can be used in the upper atmosphere measurements. Resonance fluorescence lidars are measuring intensity at shifted wavelength using of Doppler technique (Bills 1991; She and Yu 1994) or Boltzmann technique (Gelbwachs 1994). Fluorescence lidar is used to measure metallic species in the upper layer of the atmosphere $(\sim 90 \mathrm{~km})$ such as, $\mathrm{Na}, \mathrm{K}, \mathrm{Li}$ (Jegou, M.Chanin et al. 1980), Ca and Fe (Granier, J. P. Jegou et al. 1989; Gardner, C. S. et al. 1993) and/or volcanic stratospheric aerosol, polar stratospheric clouds (PSCs), gravity waves, and stratospheric ozone layer. This lidar has high sensitivity and accuracy. It is also, used to determination of wind, temperature, and study of thermal structure and complex atmospheric dynamics.

\section{Lidar wavelengths}

Based on the wavelength that been used in lidar measurements, one can classify lidar into: Elastic, inelastic, multi wavelength, and femto-second white light lidars. Brief descriptions are introduced in the following sub-sections.

\subsection{Elastic lidar}

An elastic scattering is defined as light scattering with no apparent wavelength shift or change with the incident wavelength. Elastic backscatter lidar operation, as one of the most popular lidar systems, is based on the elastic scattering physical process. It is detecting the total atmospheric backscatter of molecular and particle together without separation. Hence, elastic backscattering lidar is the sum of Rayleigh and Mie scatterings. The main 
disadvantage of elastic lidar is the difficulty of separating Mie form Rayleigh signals. More details explain how to overcome this disadvantage are given as follow.

1. It is difficult to determine accurately the volume extinction coefficient of the particles or aerosol, where we can not separate Mie form Rayleigh signals. In this case, we have to assume the a value for particle lidar ratio, $S_{a}(R)$, where $S_{a}(R)=\frac{a_{a}(R)}{\beta_{a}(R)}$, to solve the lidar equation for the aerosol extinction coefficient $\left(\alpha_{a}(R)\right)$. This assumption is impossible to estimate reliably; since the aerosol lidar ratio $S_{a}(R)$ varies strongly with the altitude $\left(S_{a}(R)\right.$ varies between 20 and 100) due to the relative humidity increment with the altitude ( $\mathrm{S}$ ratio depends on chemical, physical and morphological properties of the particles which are relative humidity dependent). As shown in Table 1 (Kovalev and Eichinger 2004), big variations of aerosol typical lidar ratio for different aerosol types have been determine at $532 \mathrm{~nm}$ wavelength using Raman lidar. Figure 2 shows a lidar return signal on June 30, 2004 at the CCNY site. The figure also shows an example of the aerosol lidar ratio $S_{a}(R)$ retrieval between 20 and 100 .

\begin{tabular}{|cc|}
\hline Aerosol (particle) types & Aerosol lidar ratio $S_{a}(R)$ (sr) \\
\hline Marine Particle & $20-35$ \\
Saharan dust & $50-80$ \\
Less absorbing urban particles & $35-70$ \\
Absorbing particles from biomass burning & $70-100$ \\
\hline
\end{tabular}

Table 1. Different aerosol types and the corresponding aerosol lidar ratio $S_{a}(R)$

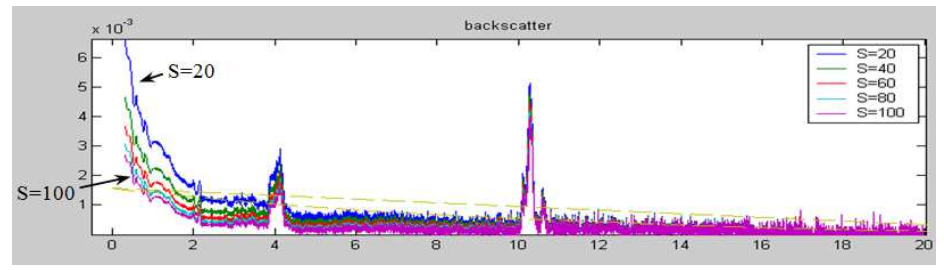

Fig. 2. CCNY lidar retrieval for $S_{a}(R)$ ration, June 30, 2004

To determine the aerosol lidar ratio $S_{a}(R)$, we can use (a) Raman lidar and High Spectra Resolution Lidar (HSRL) to get the extinction profile for particle then $S_{a}(R)$, Alternatively (b) sun-photometer observatory can be used to obtain the optical depth then seeking a solution by back integration. More details are given below.

a. Using Raman lidar and High Spectra Resolution Lidar (HSRL) to determine the extinction profile for particle and the particle backscatter coefficient can be obtained directly as well. These two lidars detect a separate backscatter signals from particle and molecular.

b. Using Sun-photometer observatory to obtain the optical depth (integration over the extinction coefficient profile) for both aerosol and molecule. Initially, in this method, we consider the reference boundary condition at the top of the lidar range is constant 
( $R_{\max }$, where the particle backscatter coefficient $\beta_{a}\left(R_{\max }\right)$ is negligible compared to the known molecular backscatter value). Second, we seek a solution by back integration (Klett 1981) that is more stable than the corresponding forward solution. Therefore, given the following data set $\left\{S_{a}, \beta_{a}\left(R_{\max }\right)\right\}$, the lidar signal can be inverted to obtain both $\beta_{a}(R), \alpha_{a}(R)$. Consequently, an estimation of the data set $\left\{S_{a}, \beta_{a}\left(R_{\max }\right)\right\}$ is required and the approach that used to analyze the lidar signals and estimate the optical coefficient error is outlined in (Hassebo et al, 2005). Finally, elastic scattering is unable to identify the gas species but can detect and measure particles and clouds (Fhjii and Fukuchi 2005).

\subsection{Inelastic backscattering lidar}

The transmitted wavelength is different than the detected wavelength on inelastic lidars. An example of inelastic lidar is Raman Lidar. A Raman signal is very weak; therefore Raman lidar operations are restricted to the nighttime due to the strong background solar radiations during the daytime. Three ways to overcome this difficulty, they are: (1) running Raman lidar within the solar-blind region (230-300 nm), (2) second is applying narrow-bandpass filter or FabryPerot interferometer, and (3) the third method is operating Raman lidar in the visible band of the spectra, during the daytime, and deduct the background solar radiation noise.

1. The first method is running Raman lidar within the solar-blind region (230-300 nm), where the ozone layer in the stratosphere $(20-30 \mathrm{~km})$ absorbs the lethal solar radiation in this spectral interval. Consequently, lidar can be operated diurnally in the solar-blind region without getting affected by the solar background noise. However, the main drawback of running lidar in this region is the attenuation of the transmitted and the returned signals by the stratospheric ozone. Another drawback is the eye hazard issue. Using this technique, in 1980th, there were some attempts to measure water vapor and temperature using multiwavelength in the solar-blind region (Renaut 1980; Petri 1982).

2. The second method is applying a narrow-bandpass filter or Fabry-Perot interferometer (Kovalev 2004). But the flitter will attenuate the signal strength as well. This is considered the main disadvantage of this method.

3. The third method has been proposed by Hassebo et al. in 2005 and 2006. The principal idea is to operate Raman lidar in the visible band (607 nm for $\mathrm{N}_{2}, 407 \mathrm{~nm}$ for water vapor, and $403 \mathrm{~nm}$ for liquid water vapor) of the spectra and then deduct the background solar radiation noise, simultaneously during the daytime optimally. This objective can be accomplished by using a polarization discrimination technique to discriminate between the sky background radiation noise and the backscattering signal. This can be approached using two polarizers at the transmitter and the receiver optics (Hassebo, B. Gross et al. 2005; Hassebo, Barry M. Gross et al. 2005; Hassebo, B. Gross et al. 2006). This technique improved the lidar Signal-to-Noise Ration (SNR) up to $300 \%$, and the attainable lidar range up to $34 \%$. A discussion of this technique is introduced in section 2 of this chapter.

\subsection{Multiple wavelength lidar}

If the lidar transmitter is a single wavelength laser, the lidar is called single wavelength lidar. However, the lidar is referred to as a multiple wavelength lidar if it is transmitting more than one wavelength. All transmitted light into the atmosphere with wavelength shorter than 300 $\mathrm{nm}$ is absorbed by ozone and oxygen (solar-blind region). Wavelengths shorter than $300 \mathrm{~nm}$ 
are fatal wavelengths. Consequently the minimum wavelength for elastic lidar is approximately $300 \mathrm{~nm}$. The commonly used wavelengths in lidar operations are near infrared $(1064 \mathrm{~nm})$, visible $(532 \mathrm{~nm})$, and ultraviolet $(335 \mathrm{~nm})$ for backscatter lidars, $(607 \mathrm{~nm})$ for N2, $(407 \mathrm{~nm})$ for water vapor, and $(403 \mathrm{~nm})$ for liquid water vapor. The multiple wavelength backscatter lidar can be used to distinguish between fine particles (emitted from fog, combustion, plume and burning smoke) and big particles such as water vapor or clouds. This differentiation can be achieved using angstrom coefficient (Hassebo, Y. Zhao et al. 2005).

Another example for multiple wavelength backscatter lidar is the DIfferential Absorption Lidar (DIAL). DIAL is used to measure concentrations of chemical species such as ozone, water vapor, and pollutants in the atmosphere. A DIAL lidar uses two distinct laser wavelengths which are selected so that one of the wavelengths is absorbed strongly by the molecule of interest while the other wavelength is not. The difference in intensity of the two return signals can be used to deduce the concentration of the molecule being investigated.

\subsection{Femto-second white light lidar}

Extremely high optical power (tera-watt) can be created from femto-second ( $1 \mathrm{fsec}=10^{-15}$ sec) laser pulse with 1mj energy. That is Femto-second white light lidar (fsec-lidar). In the era of global warming and climate change, fsec-lidar is used to detect and analyze aerosol size and aerosol phase (measuring the depolarization), water vapor, and for better understanding of forecasting, snow and rain. The inaccessibility to 3-D analysis is a disadvantage of Differential Optical Absorption Spectrometer (DOAS) and Fourier Transform Infrared spectroscopy (FTIR). This disadvantage has been conquered by Fseclidar white light lidar. At the same time it has the multi-component analysis capability of DOAS and FTIR by using a wide band light spectrum (from UV to IR); e.g. visible (Wöste, Wedekind et al. 1997; Rodriguez, R. Sauerbrey et al. 2002). An example of fsec-lidar, based on the well-known chirp pulse amplification (CPA) technique, is the $350 \mathrm{~mJ}$ pulse with 70 fsec duration and peak power of 5 TW at wavelength of $800 \mathrm{~nm}$ (Fhjii and Fukuchi 2005).

\section{Purposes of lidar measurements}

The purpose of Lidar Measurements is an additional way to classify lidars. Aerosol, clouds, and Velocity and Wind Lidars are introduced briefly in the following sub-sections.

\subsection{Aerosol lidar}

The atmosphere contains not only molecules but also particulates and aerosols including clouds, fog, haze, plumes, ice crystals, and dust. The aerosol is varied in radius; from a few nanometers to several micrometers. The bigger the aerosol size the more complex the calculations of their scattering properties. Aerosol concentration varies considerably with time, type, height, and location (Stephens 1994). Aerosols absorb and scatter solar radiation (all aerosols show such degree of absorption of the ultraviolet and visible bands) and provide cloud condensation sites (Charleon 1995). Aerosol absorption degree indicates the aerosol type. Atmospheric aerosol altitude, size, distribution and transportation are major global uncertainties due to their effects on controlling the earth's planet climate stability and global warming issues. In addition of the impact of aerosol in the atmospheric global climate change (Charlson, J. Langner et al. 1991; Charlson, S. E. Schwartz et al. 1992), it also affects human 
health with diseases such as lung cancer, bronchitis, and asthma. These have been essential motivations to study aerosol properties and transportation. Lidars have been successfully applied to study stratospheric aerosols mainly sulfuric-acid/water droplet (Zuev V., V. Burlakov et al. 1998), tropospheric mixture aerosols of natural (interplanetary dust particle and marine) and of anthropogenic (sulfate and soot particles) (Barnaba F and Gobbi 2001) and climate gases such as stratospheric ozone (Douglass L. R., M.R. Schoeberl et al. 2000) as well as for analyzing the clouds properties (Stein, Wedekind et al. 1999). Aerosol sources can origin from nitrate particles, sea-salt particles, and volcanic ashes and rubble. Aerosol particle sizes were categorized as aitken, large, and giant particles (Junge 1955), where: (a) Dry radii < 0.1 $\mu \mathrm{m}$, Aitken particles, (b) Dry radii $0.1 \mu \mathrm{m}<\mathrm{r}<1 \mu \mathrm{m}$, large particles, and (c) Dry radii $\mathrm{r}>1 \mu \mathrm{m}$, giant particles. Aerosol concentration decreases with increasing altitude. $80 \%$ of the aerosols condense in the lowest two kilometers of the troposphere (i.e., within the Planetary Boundary Layer (PBL)) as shown in Fig 3, for New York City on August 11, 2005.
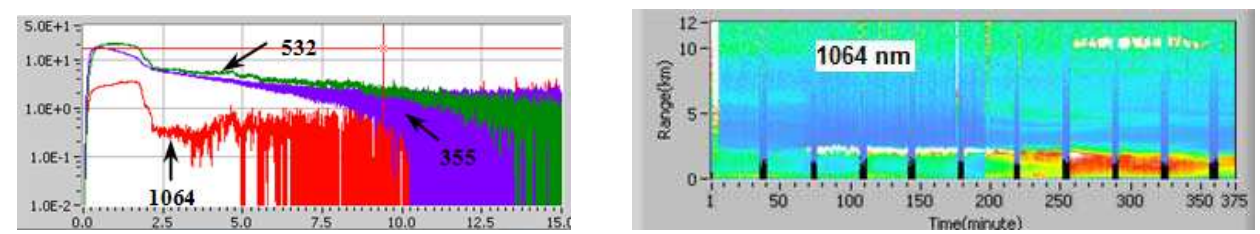

Source: CCNY lidar system

Fig. 3. New York City aerosol PBL, Aug 11, 2005

The extinction profile is considered a high-quality indicator (in the cloud free case) of aerosol concentration. A principle of measuring aerosol is using the wavelength between 300-1100 nm to determine the particle extinction and backscattering profiles. A good example for lidar, that has been used to monitor aerosol without attendance, is Micro-Pulse Lidar (MPL) (Spinhirne 1991; Spinhirne 1993; Welton, Campble et al. 2001). CUNY MPL at LaGuardia Community College will play a significant role in studying the impact of the anthropogenic aerosol on human health, life, air quality, climate change, and earth's radiation budget once it is deployed. High Spectral Resolution Lidar (HSRL) can be used, as well, to measure aerosol scattering cross section, optical depth, and backscatter phase function in the atmosphere. This can be achieved by separating the Doppler-broadened molecular backscatter return from the un-broadened aerosol return. The molecular signal is then used as a calibration target which is available at each point in the lidar profile.

\subsection{Cloud lidar}

Cloud particle radius is larger than $1 \mu \mathrm{m}$ (between about $2 \mu \mathrm{m}$ to around $30 \mu \mathrm{m}$ ), which is bigger than the lidar wavelength (300- $1100 \mathrm{~nm})$. Therefore lidars cannot measure the cloud size distribution (Fhjii and Fukuchi 2005). However, lidars can detect the cloud ceiling, thickness, and its vertical profile where the lidar return signal from the cloud is very strong (because cloud behaves as obstruction in the laser propagation path).

As shown in Fig 4, using three wavelengths of 355, 532, and $1064 \mathrm{~nm}$, the CCNY stationary lidar detected clouds vertical structure between 3.5 to $4.5 \mathrm{~km}$ height, and the planetary boundary layer (Welton, Campble et al.) on January 25, 2006. 

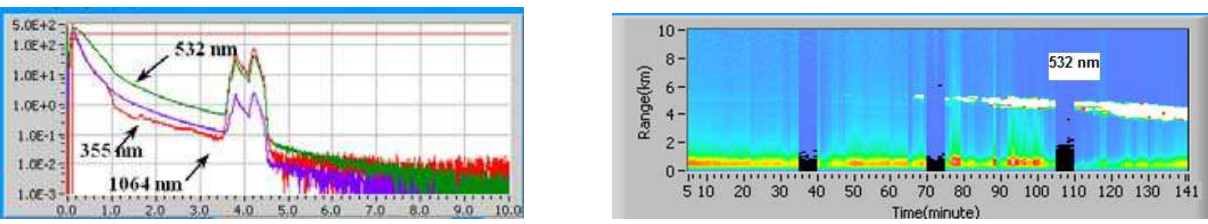

Source: CCNY lidar

Fig. 4. CCNY lidar data shows cloud ceiling, thickness, and structure, Jan 25, 2006

Clouds cover approximately $50 \%$ of the earth (Liou 2002). Based on the altitude (i.e., temperature) clouds are formed in liquid or solid (crystal) phases. Clouds and their interaction with aerosol and their impact on local and global climate change encouraged NASA to create various projects to monitor and study clouds distribution, thickness, transportation, and observe transitional form of clouds or combination of several forms and varieties. Cloud-Aerosol Lidar and Infrared Pathfinder Satellite Observations (CALIPSO), Micro-Pulse Lidar (MPL), and Polarization Diversity Lidar (PDL is a lidar with two channels to detect two polarizations (Fhjii, 2005; Sassen, 1994)) are well-known lidars to measure and detect clouds. Measuring cloud phase is based on Mie scattering theory, the backscattering from non-spherical (e.g., crystal phase) particles changes the polarization strongly, but the spherical (water droplets) particles do not (Sassen, K. et al. 1992; Sassen 1994). Both spherical and non-spherical cloud particles have a degree of depolarization $\left(\delta=I_{\perp} / I_{\mid}\right)$due to the multiple scattering effects, where $I_{\perp}, I_{\mid}$are respectively the perpendicular and the parallel intensity components for the incident light. But non-spherical cloud particles degree of depolarization is greater than spherical particles depolarization $\left.\left(\delta_{N S}\right\rangle \delta_{S}\right)$. Polarization lidars are used to differentiate between cloud liquid and sold phases.

Fig 5, shows thin cloud signals that were provided by Hassebo et al. on January 10, 2006 using elastic Mie scattering stationary lidar at the City College of NY site (longitude 73.94 W, latitude $40.83 \mathrm{~N}$ ), at 355, 532, and $1064 \mathrm{~nm}$ wavelengths. Comparing the thin cloud signal (Fig 5) with Fig 4 (thick cloud signal) we noted that, as a result of laser rapid attenuation while it is penetrating the cloud, in the thin cloud case the visible beam had a sufficient intensity to open a channel with high optical transparency to a higher altitude. In contrast, in Fig 4 the cloud was thick enough to prevent the laser beams from increasing their depth of penetration into the layer beyond the cloud. That explains the useless noisy (UV and IR) signals after the cloud ceiling $(R=4.5 \mathrm{~km}$, and $R=11.5 \mathrm{~km})$ in both cases, and for visible signal in the heavy cloud case even when the altitude is low $(4.5 \mathrm{~km})$. We noted also the PBL was shown clearly in both cases where the aerosol loading in New York City is always high.
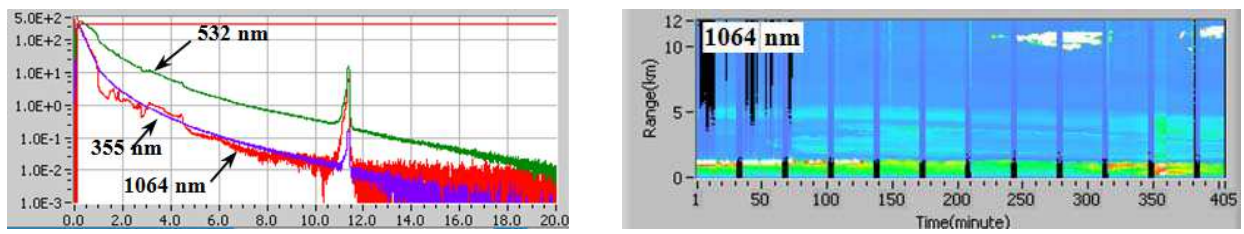

Fig. 5. CCNY Lidar backscattering signals show thin cloud at 11km, Jan 10, 2006. 


\subsection{Velocity and wind lidar}

Doppler lidar can be used to provide the velocity of a target. When the light transmitted from the lidar hits a target moving towards or away from the lidar, the wavelength of the light reflected/scattered off the target will be changed slightly. This is known as a Doppler shift, hence Doppler lidar. If the target is moving away from the lidar, the returned beam will have a longer wavelength (sometimes referred to as a red shift). In other hand, if the target is moving towards the lidar the return light will be at a shorter wavelength (blue shifted). The target can be either a hard target or an atmospheric target. Thus the same idea is used to measure the wind velocity where, the atmosphere contains many microscopic dust and aerosol particles (atmospheric target) which are carried by the wind.

\section{Lidar types based on platform}

\subsection{Ground-based lidar}

The PBL is the most important layer to study in the earth's atmosphere. Ground-based lidar (stationary in laboratories and mobiles in vehicles stations) is providing us with continuous, stable, and high resolution measurements of almost most of the lower atmosphere parameters. Ground-based lidar has made an important contribution in correcting the satellite data and complete the missing parts from the satellite images. A good example in chapter 7 of this thesis shows how the ground-based lidar signature is supporting the satellite operations to discriminate between cloud (big particle) and smoke plume (fine particle) and to determine the plumes height and thickness which the satellite cannot provide. The main drawback of ground-based lidar is the limitation of running during the bad weather (rain or snow) and the air control regulations issues.

\subsection{Air-borne lidar}

Due to the uncertainty in validation of some remote sensing methodologies, particularly to detect cloud and measure its properties, from ground-based lidar stations, the in situ probes are useful techniques. Also the inaccessibility of the object of interest from the ground-based or space-based systems is the other reason to use air-borne lidars. The air-borne lidar platforms are air-craft, balloon, and helicopter. Applications of using air-borne lidars are to measure aerosol, clouds, temperature profile, metals in the mesopause, ozone in the stratosphere, wind, PSCs, $\mathrm{H}_{2} \mathrm{O}$, and on land, water depth, submarine track, oil slicks, etc (Fhjii and Fukuchi 2005). One of the disadvantages of these platforms is the vibration problem.

\subsection{Space-based lidar}

The ground-based lidar provides a one spot at a unique moment measurement on the earth surface. The air-borne lidars are limited in one country or specific region as well as restricted by the weather or some times politic circumstances. The merit of the space-based lidar is to give global and/or continental images of the earth's atmosphere properties, structure, and activities. Certainly, space-based lidar needs very sophisticated, extremely expensive equipment, especially for remotely control the unattended operations and adaptive optics issue. In additional to the extremely important understanding of global scale phenomena $\left(\mathrm{H}_{2} \mathrm{O}\right.$ and carbon cycles, climate change, global warming, etc.) we have gained, we can reach 
an inaccessible areas by air-borne and/or ground-based stations such as oceans, north and south poles.

\section{Lidar configurations}

Essentially, there are two basic configurations for lidar systems; monostatic and bistatic configurations.

\subsection{Monostatic lidar}

Monostatic configuration is the typical configuration for modern systems. It is employed with pulsed laser source providing very good vertical resolution and beam collimation compared with the bistatic configuration. In monostatic configurations, the transmitter and receiver are at the same location, (see Fig. 6). Monostatic systems can be classified into two categories, coaxial systems and biaxial systems. Monostatic system was first used in 1938.

\subsubsection{Monostatic coaxial lidar}

In the Monostatic coaxial configuration the axis of transmitter laser beam is coincident with the receiver's telescope Field Of View (FOV) as shown in Figure 6 (a). The main disadvantages in the Configuration are the detector saturation problem that occurs once the lidar laser beam is shot, the unwanted signal that is detected from reflection of the transmitted light at the transmitter optics in the top of the receiver telescope, and the portion of the images - for short range - that are blocked by the secondary mirror.

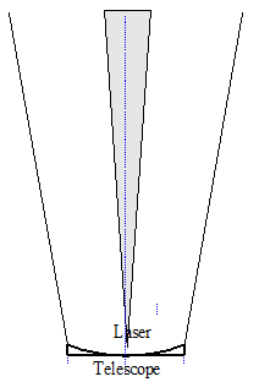

(a) Monostatic coaxial

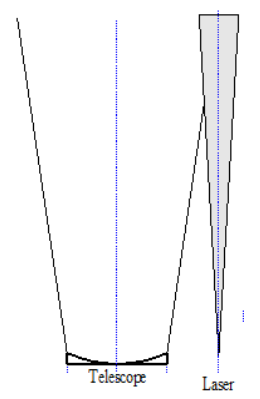

(b) Monostatic biaxial

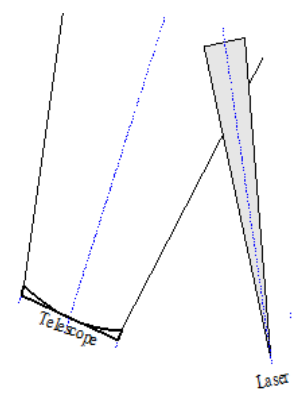

(c) Bi-static

Fig. 6. Field of view arrangements for lidar laser beam and detector optics

\subsubsection{Monostatic biaxial lidar}

In the Monostatic biaxial arrangement the transmitter and receiver are located adjacent to each other. Under this circumstance the laser beam will intersect with the receiver telescope VOF beyond specific range $R$. This range can be predetermined based on the distance between the laser FOV and telescope FOV axes. In fact, this configuration is quite useful in preventing the receiver photomultiplier (PMT) detectors saturation from the near-filed laser radiations (coaxial lidar disadvantage). However, in a biaxial lidar system, the detected signals are negatively affected by the geometrical form factor (GF) at shorter range. This effect makes near field measurements impossible (Measures 1984). Hassebo et al. proposed 
two techniques to overcome the problems of geometrical form factor (Hassebo, R. Agishev et al. 2004).

\subsection{Bistatic configuration}

Bistatic lidar configuration is involving a considerable separation between the laser transmitter and the receiver subsystems. However, the usefulness of this configuration was originally used in supporting lidar with continuous wave (cw) laser source to overcome the prevention of measuring of the height variation of the density caused by cw laser (Fhjii and Fukuchi 2005). Currently, this arrangement is rarely used (Measures 1984).

As a summary of some lidar physical processes, their corresponding applications and objective of measurements are given in Table 2 .

\begin{tabular}{|c|c|c|c|c|c|}
\hline \multicolumn{6}{|c|}{ Lidar Type Based On } \\
\hline Process & Wavelength & Objective & Platform & Configurations & Other \\
\hline $\begin{array}{l}\text { Rayleigh } \\
\text { Doppler }\end{array}$ & Elastic & Wind & $\begin{array}{l}\text { Ground- } \\
\text { based }\end{array}$ & Monostatic & $\begin{array}{l}\text { Stratosphere } \\
\text { Mesopause }\end{array}$ \\
\hline Backscatter & inelastic & Cloud & Air-borne & Monostatic & Troposphere \\
\hline $\begin{array}{l}\text { Mie } \\
\text { Backscatter } \\
\text { Raman } \\
\end{array}$ & $\begin{array}{l}\text { single WL } \\
\text { Multiple WL }\end{array}$ & $\begin{array}{l}\text { Aerosol } \\
\mathrm{H}_{2} \mathrm{O}\end{array}$ & $\begin{array}{l}\text { Ground- } \\
\text { based } \\
\text { Space-based }\end{array}$ & $\begin{array}{l}\text { Monostatic } \\
\text { (Biaxial and } \\
\text { Coaxial) }\end{array}$ & $\begin{array}{l}\text { Troposphere } \\
\text { Stratosphere }\end{array}$ \\
\hline Raman & $\begin{array}{l}\text { DIAL } \\
\text { Raman DIAL }\end{array}$ & $\begin{array}{l}\text { Ozone } \\
\text { Humidity } \\
\text { gaseous }\end{array}$ & $\begin{array}{l}\text { Ground- } \\
\text { based }\end{array}$ & Monostatic & Troposphere \\
\hline Fluorescence & & $\begin{array}{l}\text { Wind / Heat } \\
\text { flux }\end{array}$ & Air-borne & Monostatic & mesosphere \\
\hline
\end{tabular}

Table 2. Lidar classification and related research

\section{Improve lidar signal-to-noise ratio during daytime operations}

In this section, the impact and potential of a polarization selection technique to reduce sky background signal for linearly polarized monostatic elastic backscatter lidar measurements are examined. Taking advantage of naturally occurring polarization properties in scattered sky light, a polarization discrimination technique was devised. In this technique, both lidar transmitter and receiver track and minimize detected sky background noise while maintaining maximum lidar signal throughput. Experimental Lidar elastic backscatter measurements, carried out continuously during daylight hours at $532 \mathrm{~nm}$, show as much as a factor of $\sqrt{10}$ improvement in signal-to-noise ratio (SNR) and the attainable lidar range up to $34 \%$ over conventional un-polarized schemes. Results show, for vertically pointing lidars, the largest improvements are limited to the early morning and late afternoon hours. The resulting diurnal variations in SNR improvement sometimes show asymmetry with solar angle, which analysis indicates can be attributed to changes in observed relative humidity that modifies the underlying aerosol microphysics and observed optical depth. 


\subsection{Introduction}

This work describes a technique which is designed to improve the operation of conventional elastic backscatter lidars in which the transmitted signal is generally linearly polarized. The technique requires the use of a polarization sensitive receiver. Polarization selective lidar systems have, in the past, been used primarily for separating and analyzing polarization of lidar returns, for a variety of purposes, including examination of multiple scattering effects and for differentiating between different atmospheric scatterers and aerosols (Schotland, K. Sassen et al. 1971; Hansen and Travis 1974; Sassen 1974; Platt 1977; Sassen 1979; Platt 1981; Kokkinos and Ahmed 1989; G.P.Gobbi 1998; Roy, G. Roy et al. 2004). In the approach described here, the polarized nature of the sky background light is used to devise a polarization selective scheme to reduce the sky background power detected in a lidar. This leads to improved signal-to-noise ratios (SNR) and attainable lidar ranges, which are important considerations in daylight lidar operation (Hassebo, B. Gross et al. 2005; Hassebo, Barry M. Gross et al. 2005; Ahmed, Y. Hassebo et al. 2006; Ahmed, Yasser Y. Hassebo et al. 2006; Hassebo, B. Gross et al. 2006). The approach, discussed here, is based on the fact that most of the energy in linearly polarized elastically backscattered lidar signals retains the transmitted polarization (Schotland, K. Sassen et al. 1971; Hansen and Travis 1974; Kokkinos and Ahmed 1989), while the received sky background power (Welton, Campble et al.) observed by the lidar receiver shows polarization characteristics that depend on both the scattering angle, $\theta_{s c}$, between the direction of the lidar and the direct sunlight and the orientation of the detector polarization relative to the scattering plane. In particular, the sky background signal is minimized in the plane perpendicular to the scattering plane, while the difference between the in-plane component and the perpendicular components (i.e degree of polarization) depends solely on the scattering angle. For a vertically pointing lidar, the scattering angle $\theta_{s c}$ is the same as solar zenith angle $\theta_{s}$ Fig. 7. The degree of polarization of sky background signal observed by the lidar is largest for solar zenith angles near $\theta_{S} \approx 90^{\circ}$ and smallest at solar noon. The essence of the proposed approach is therefore, at any time, to first determine the parallel component of the received sky background $(\mathrm{Pb})$ with a polarizing analyzer on the receiver, thus minimizing the detected $\mathrm{Pb}$, and then orienting the polarization of the outgoing lidar signal so that the polarization of the received lidar backscatter signal is aligned with the receiver polarizing analyzer. This ensures unhindered passage of the primary lidar backscatter returns, while at the same time minimizing the received sky background $\mathrm{Pb}$, and thus maximizing both $\mathrm{SNR}$ and attainable lidar ranges.

The experimental approach and system geometry to implement the polarization discrimination scheme are described in the next Section. Section 1.8.3 presents results of elastic lidar backscatter measurements for a vertically pointing lidar at $532 \mathrm{~nm}$ taken on a clear day in the New York City urban atmosphere, that examine the range of application of the technique. In particular, the diurnal variations in $\mathrm{Pb}$ as functions of different solar angles are given and the SNR improvement is shown to be consistent with the results predicted from the measured degree of linear polarization, with maximum improvement restricted to the early morning and late afternoon. Section 1.8.4 examines the situations in which asymmetric diurnal variations in sky $\mathrm{Pb}$ are observed, and demonstrates the possibility that an increase in relative humidity (Halldorsson and Langerhoic), consistent with measured increases in measured Precipitable water vapor (PWV) and aerosol optical depth (AOD), may account for the asymmetry. Analysis of the overall results is presented in Section 1.8.5, 


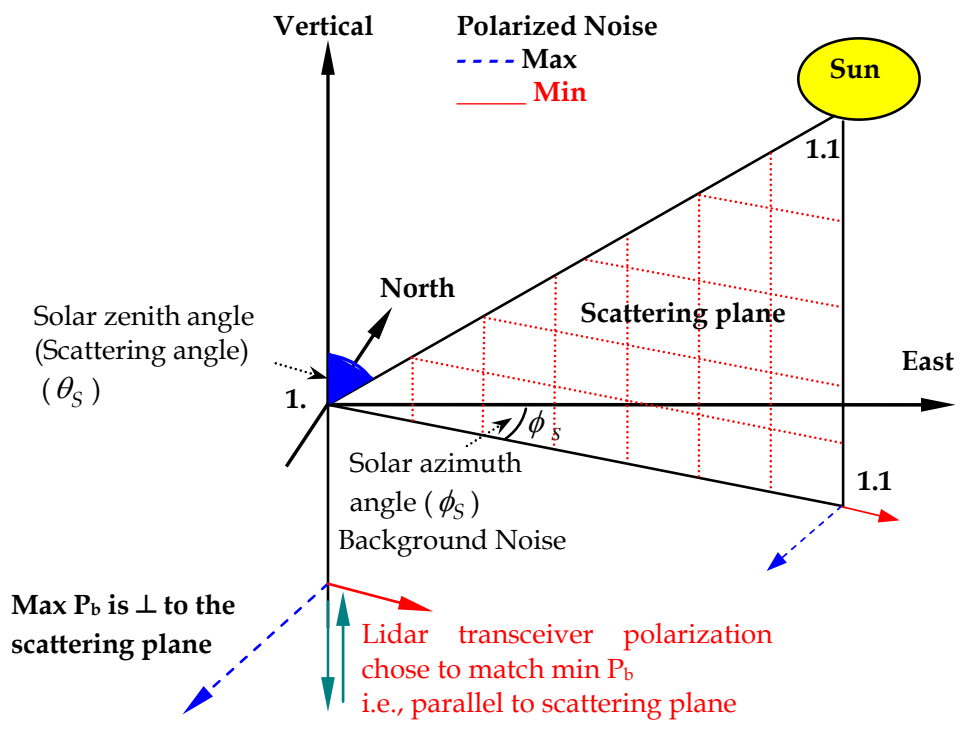

Lidar

Transceiver

Fig. 7. Sky background suppression geometry for a vertical pointing lidar:

$\theta_{s}$ is the solar zenith angle (equal to the scattering angle for this geometry)

$\phi_{s}$ is the solar azimuth angle; and $\mathrm{OAB}$ is the solar scattering plane

where the SNR improvement factor is compared with a single scattering radiative transfer theory. Possible modifications due to multiple scattering are also explored.

In Section 1.8.6, the diurnal variation of the polarization rotation angle is compared to the theoretical result and an approach for automation of the technique based on theory is discussed. Conclusions and summary are presented in Section 1.8.7.

\subsection{Experimental approach and system geometry}

The City University of New York (CUNY) has developed two ground-based lidar systems, one mobile and one stationary, that operate at multiple wavelengths for monostatic elastic backscatter retrievals of aerosol and cloud characteristics and profiles. Lidar measurements are performed at the Remote Sensing Laboratory of the City College of New York, (CCNY). The lidar systems are designed to monitor enhanced aerosol events as they traverse the eastern coast of the United States, and form part of NOAA's Cooperative Remote Sensing Center (NOAA-CREST) Regional East Atmospheric Lidar Mesonet (REALM) lidar network. The lidar measurements, reported here, were carried out with the mobile elastic monostatic biaxial backscatter lidar system at the CCNY site (longitude $73.94 \mathrm{~W}$, latitude $40.83 \mathrm{~N}$ ), at $532 \mathrm{~nm}$ wavelength. The lidar transmitter and the receiver subsystems are detailed in Table 3.

The lidar return from the receiver telescope is detected by a photo-multiplier (PMT R11527P) with a $1 \mathrm{~nm}$ bandwidth optical filter (532F02-25 Andover), centered at the $532 \mathrm{~nm}$ 


\begin{tabular}{|c|c|c|c|}
\hline \multicolumn{2}{|c|}{ Transmitter } & \multicolumn{2}{|c|}{ Receiver } \\
\hline Laser & $\begin{array}{l}\text { Q-Switched Nd: YAG } \\
\text { Continuum Surelite 1l-10 }\end{array}$ & $\begin{array}{l}\text { Telescope } \\
\text { Aperture }\end{array}$ & $\begin{array}{l}\text { CM_1400 Schmidt } \\
\text { Cassegrian telescope } \\
35.56 \mathrm{~mm}\end{array}$ \\
\hline Wavelength & $1064,532,355 \mathrm{~nm}$ & Focal length & $3910 \mathrm{~mm}$ \\
\hline Energy/pulse & $\begin{array}{l}650 \mathrm{mj} \text { at } 1064 \mathrm{~nm} \\
300 \mathrm{mj} \text { at } 532 \mathrm{~nm} \\
100 \mathrm{mj} \text { at } 355 \mathrm{~nm}\end{array}$ & $\begin{array}{l}\text { Detectors } \\
532 \mathrm{~nm} \\
355 \mathrm{~nm} \\
1064 \mathrm{~nm}\end{array}$ & $\begin{array}{l}\text { Hamamatsu } \\
\text { PMT: R11527 P } \\
\text { PMT: R758-10 } \\
\text { APD }\end{array}$ \\
\hline Pulse Duration & $7 \mathrm{~ns}$ at $1064 \mathrm{~nm}$ & Data Acquisition & LICEL TR 40-160 \\
\hline Repetition Rate & $10 \mathrm{~Hz}$ & Photon Counting & LICEL TR 40-160 \\
\hline $\begin{array}{l}\text { Harmonic } \\
\text { Generation }\end{array}$ & $\begin{array}{l}\text { Surelite Double (SLD) } \\
\text { Surelite Third Harmonic } \\
\text { (SLF) }\end{array}$ & & \\
\hline
\end{tabular}

Table 3. Lidar system specifications

wavelength. For extended ranges, data is acquired in the photon counting (PC) mode, typically averaging 600 pulses over a one minute interval and using a Licel 40-160 transient recorder with $40 \mathrm{MHz}$ sampling rate for A/D conversion and a $250 \mathrm{MHz}$ photon counting sampling interval. Fig. 8 shows the arrangement used to implement the polarization-

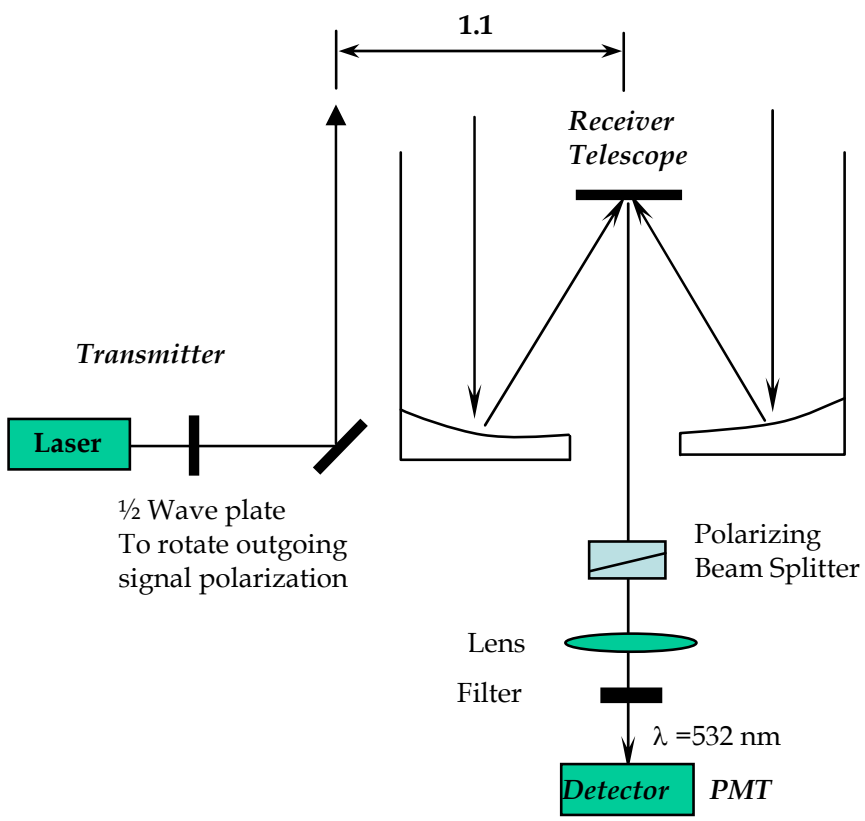

Fig. 8. Schematic diagram of polarization experiment set up for elastic biaxial monostatic lidar (mobile lidar system) 
tracking scheme. To select the polarization of light entering the detector, a polarizing beam splitter is located in front of the collimating lens that is used in conjunction with a narrow band filter (alternatively, dichroic material polarizers were also used).

This polarizing beam splitter (analyzer) is then rotated to minimize the detected sky background $\mathrm{Pb}$. Cross polarized extinction ratios on the receiver analyzer were approximately 10-4 . On the transmission side, a half wave plate at the output of the polarized laser output is then used to rotate the polarization of the outgoing lidar beam so as to align the polarization of the backscattered lidar signal with the receiver polarizing analyzer and hence maximize its throughput (i.e., at the minimum $\mathrm{Pb}$ setting). This procedure was repeated for all measurements, with appropriate adjustments being made in receiver polarization analyzer alignment and a corresponding tracking alignment in the transmitted beam polarizations to adjust for different solar angles at different times of the day, and hence minimize the detected $\mathrm{Pb}$ and maximize lidar SNR.

\subsection{Results}

Figures 9- to- 11 show experimental results with the receiver analyzer oriented to minimize $\mathrm{Pb}$ and a corresponding tracking lidar polarization orientation to maximize the detected backscattered lidar signal and its SNR at different times on Oct 07, 2004 (6:29 PM, 3 PM, and noon). All times given are in (EST) Eastern Standard Time.

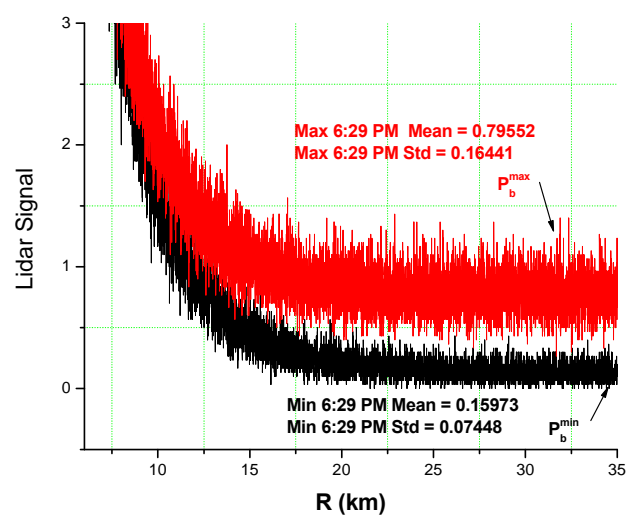

Fig. 9. Comparison of max Pb verses min Pb lidar signals at 6:29 PM on 07 October 2004.

The detected lidar signal is the sum of atmospheric backscatter of the laser pulse and the detected background light. The upper trace corresponds to the receiver polarization analyzer oriented to minimize $\mathrm{Pb}$ and the lidar transmitter polarization oriented to maximize the detected backscattered lidar signal while the lower trace is the result when orthogonal orientations of both receiver analyzer and lidar polarization are used, minimizing the sky background component in the return signal. Similar measurements were made at 3:00 PM and noon on the same day as shown in Figures 4 and 5 respectively.

Fig. 12 shows the resulting return signals in the far zone where the sky background signal is the dominant component (20-30 km range) for these times and for both orthogonal polarizations. 


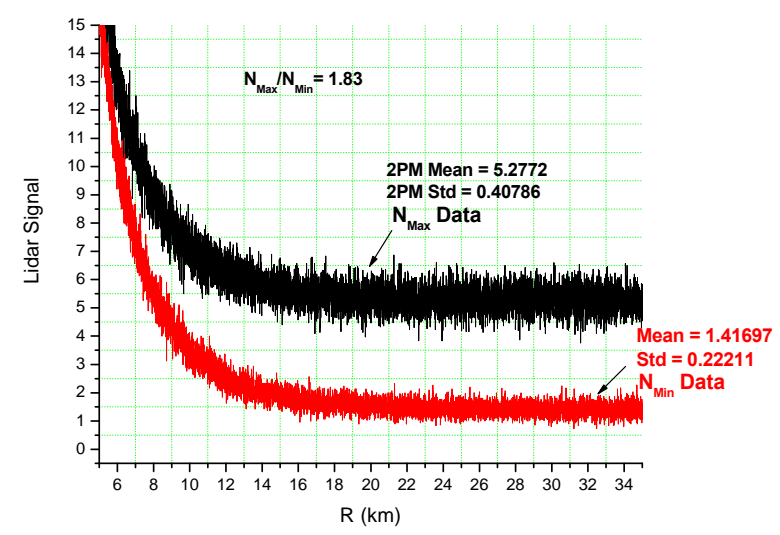

Fig. 10. Comparison of max max $\mathrm{Pb}$ (NMax) verses min $\mathrm{Pb}$ (NMin) lidar signals at $3 \mathrm{PM}$ (EST) on 07 Oct 2004: Range $35 \mathrm{~km}$, Lidar signal in linear scale

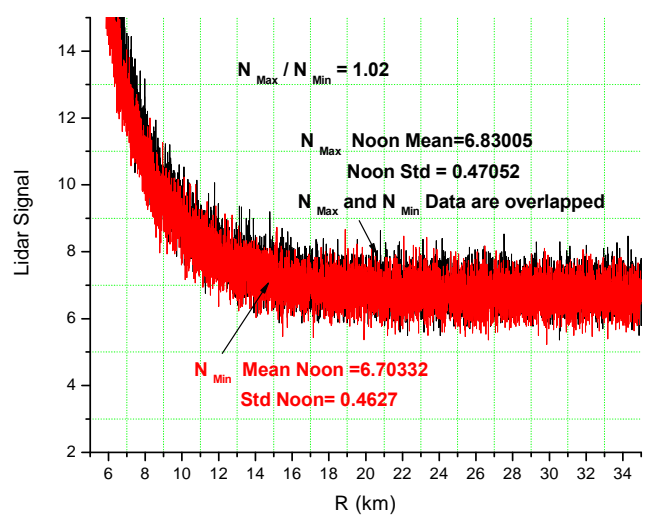

Fig. 11. Comparison of max $\mathrm{Pb}$ (NMax) verses min $\mathrm{Pb}$ (NMin) lidar signals at noon (EST) on 07 Oct 2004: Range $35 \mathrm{~km}$, Lidar signal in linear scale, two signals are overlapped

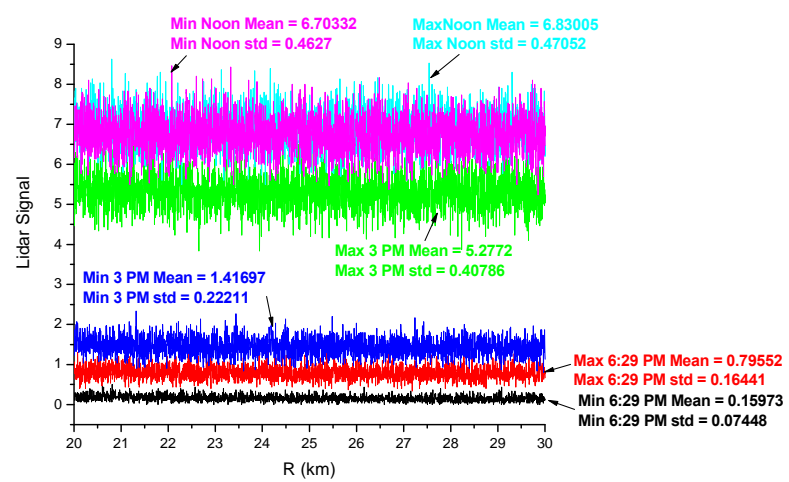

Fig. 12. Comparison of experimental return signals at 6:29 PM, 3 PM and noon on 07 Oct 2004, range of 20-30 km, both orthogonal cases are shown. 
The relative impact on the sky background signal, $\mathrm{Pb}$, of the polarization discrimination scheme is seen to be largest at 6:29 PM, when the lidar solar angle is large $\left(89^{\circ}\right)$, while at noon it is minimal. The detected signal for maximum $\mathrm{Pb}$ is much noisier than the detected signal with minimum $\mathrm{Pb}$, except in the noon measurement. This is consistent with the shot noise limit applicable to PMT's where the detected noise amplitude $\Delta P$ (standard deviation) is proportional to the square root of the mean detected background signal $\langle P\rangle$ ( i.e., $\Delta P \propto \sqrt{\langle P\rangle}$ ) where $\mathrm{P}$ is the detector output, whose mean value is proportional to $\mathrm{Pb}$. This relation is most conveniently expressed in terms of the ratios of the detected signals at the orthogonal polarization states $R=P_{b}^{\max } / P_{b}^{\min }$, in which the shot noise condition is now: $\Delta R=\sqrt{R}$. This relation has been verified in our experiments and the results summarized in Table 4.

\begin{tabular}{|lccccccc|}
\hline \multicolumn{1}{|c}{ Time } & $\left\langle P_{\min }\right\rangle$ & $\Delta P_{\min }$ & $\left\langle P_{\max }\right\rangle$ & $\Delta P_{\min }$ & $R=\frac{\left\langle P_{\max }\right\rangle}{\left\langle P_{\min }\right\rangle}$ & $\Delta R=\frac{\Delta P_{\max }}{\Delta P_{\min }}$ & $\sqrt{R}$ \\
\hline Noon & 6.7 & 0.46 & 6.83 & 0.46 & 1.2 & $\mathbf{1 . 0 1 9}$ & $\mathbf{1 . 0 9}$ \\
\hline 3:00 PM & 1.41 & 0.22 & 5.27 & 0.22 & 3.72 & $\mathbf{1 . 8 2}$ & $\mathbf{1 . 9}$ \\
\hline 6:29 PM & 0.159 & 0.074 & 0.795 & 0.074 & 5.2 & $\mathbf{2 . 2}$ & $\mathbf{2 . 2}$ \\
\hline
\end{tabular}

Table 4. Comparison of experimental results to verify shot noise operation $(\Delta R=\sqrt{R})$

In assessing the extent to which the polarization discrimination detection scheme can improve the SNR and the operating range, I compare the detected SNR with a polarizer, to that which would be obtained if no polarization filtering was used. When shot noise from background light is large compared to that from the lidar signal backscatter, the SNR improvement can be expressed in terms of an SNR improvement factor $\left(G_{i m p}\right)$ expressed in terms of maximum and minimum $\mathrm{Pb}$ measurements $\left(P_{b}^{\max }, P_{b}^{\min }\right)$ as:

$$
G_{i m p}=\frac{S N R_{\text {Max }}}{S N R_{\text {Unpol }}}=\sqrt{\left(\frac{P_{b}^{\min }+P_{b}^{\max }}{P_{b}^{\min }}\right)}=\sqrt{1+\left(\frac{P_{b}^{\max }}{P_{b}^{\min }}\right)}
$$

To examine how the decreased $\mathrm{Pb}$ translates into a SNR improvement, Fig. 13 shows the range dependent SNR obtained for both maximum and minimum noise polarization orientations for a representative lidar measurement. The results show that for $\mathrm{SNR}=10$, the range improvement resulting from polarization discrimination resulted in an increase in lidar operating range from $9.38 \mathrm{~km}$ to $12.5 \mathrm{~km}$ (a $34 \%$ improvement). Alternatively, for a given lidar range, say $9 \mathrm{~km}$, the SNR improvement was $250 \%$.

Another useful way of looking at the effect of SNR improvement is to note that the SNR improves as the square root of the detector's averaging time. Thus a $250 \%$ improvement in SNR is equivalent to reducing the required averaging time by a factor of $(1 / 2.5)^{2}$.

\subsection{SNR Improvement with respect to solar zenith angle}

The SNR improvement factor $\left(G_{i m p}\right)$ is plotted as a function of the local time, Fig. 14, and the solar zenith angle, Fig.15. Since the solar zenith angle retraces itself as the sun passes 


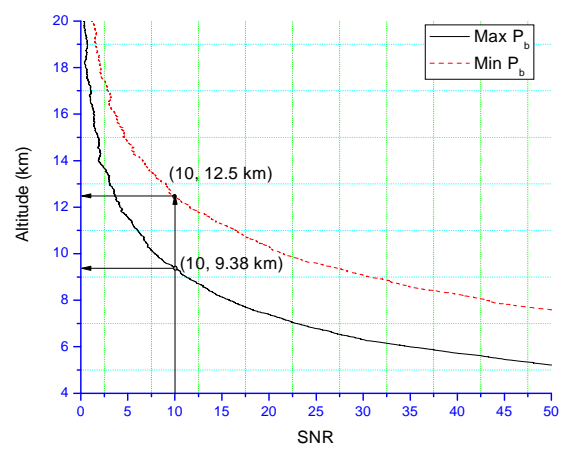

Fig. 13. Experimental range dependent SNR for maximum and minimum polarization orientations

through solar noon, it would be expected that the improvement factor $\left(G_{i m p}\right)$ would be symmetric before and after the solar noon and depend solely on the solar zenith angle. This symmetry is observed in Figs.14 and 15 for measurements made on 19 February 2005 and is supported by the relatively small changes in optical depth (AOD) values obtained from a collocated shadow band radiometer, (morning $\tau=0.08$, afternoon $\tau=0.11$ )

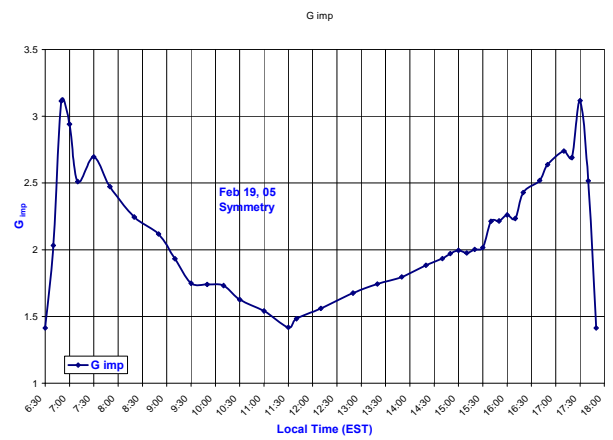

Fig. 14. Gimp in detection wavelength of $532 \mathrm{~nm}$ verses local time on 19 February 2005

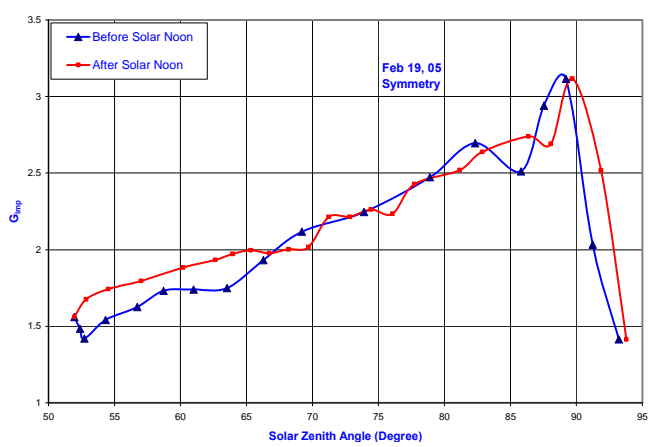

Fig. 15. Gimp in detection wavelength of $532 \mathrm{~nm}$ verses solar zenith angle on 19 February 2005 


\subsection{Effect of variable precipitable water vapor on SNR}

Symmetry was, however, not always observed in our experimental results. Fig. 16 shows Gimp plotted as a function of the solar zenith angle for 23 February 2005. Small asymmetries were observed. These appear to be related to changes in humidity, which can modify the scattering properties and lead to enhanced multiple scattering effects. The results are supported by the variation in Precipitable water vapor (PWV) shown in Fig. 17, obtained from the CCNY Global Positioning System GPS measurements which were processed by the NOAA Forecast Systems Laboratory (FSL) (NOAA Web) for both days.

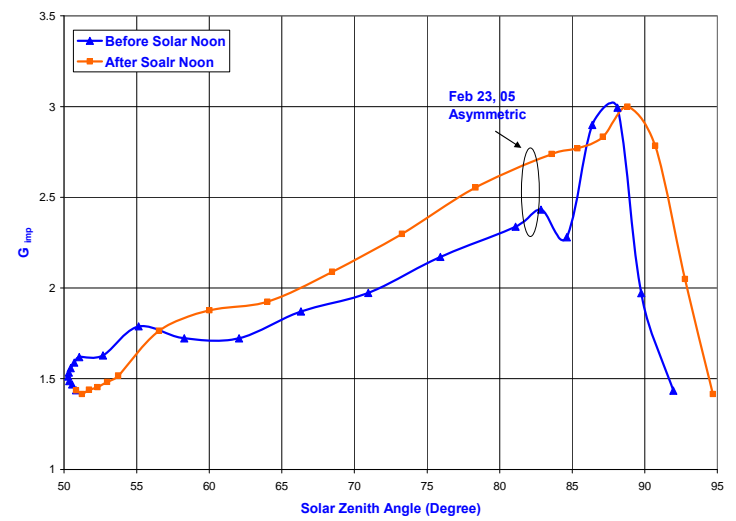

Fig. 16. Gimp in detection wavelength of $532 \mathrm{~nm}$ verses solar zenith angle on 23 February 2005

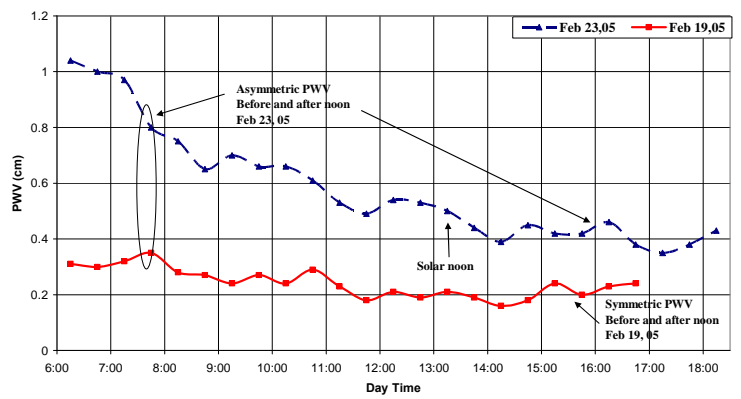

Fig. 17. PWV (cm) loading verses local time on 19 February 2005 and 23 February 2005

The 23 February the aerosol optical depth measurements from the shadow band radiometer show larger proportional changes (morning $\tau=0.16$ afternoon $\tau=0.09$ ) than those of 19 February, which are consistent with the asymmetry in the PWV, with higher optical depths corresponding to high PWV (and $\mathrm{RH} \%$ ) conditions.

\subsection{SNR improvement azimuthally dependence}

Within the single scattering theory, the polarization orientation at which the minimum $\mathrm{Pb}$ occurs should equal the azimuth angle of the sun (see Fig. 7). To validate this result, the polarizer rotation angle was tracked (by rotating the detector analyzer) over several seasons 
since February 2004 and compared with the azimuth angle calculated using the U.S. Naval Observatory standard solar position calculator (Applications) (14 April 2005). As expected, the polarizer rotation angle needed to achieve a minimum Pb closely tracks the azimuth angle, Fig. 18.

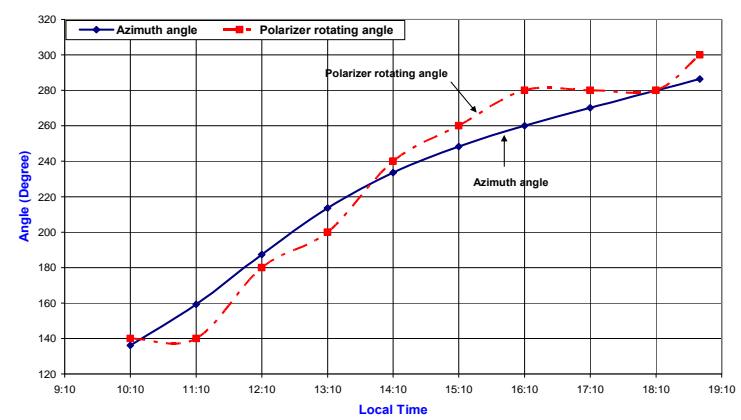

Fig. 18. Comparison between solar azimuth angle and angle of polarization rotation needed to achieve minimum Pb: 14 April 2005

This relationship is important since it allows us to conceive of an automated approach that makes use of a pre-calculated solar azimuth angle as a function of time and date to automatically rotate and set both the transmitted lidar polarization and the detector polarizer at the orientations needed to minimize $\mathrm{Pb}$. With an appropriate control system, it would then be possible to track the minimum $\mathrm{Pb}$ by rotating the detector analyzer and the transmission polarizer simultaneously to maximize the SNR, achieving the same results as would be done manually as described above.

\subsection{Conclusions and summary}

SNR improvements can be obtained for lidar backscatter measurements, using a polarization selection/tracking scheme to reduce the sky background component. This approach can significantly increase the far range SNR as compared to un-polarized detection. This is equivalent to improvements in effective lidar range of over 30\% for a SNR threshold of 10. The improvement is largest for large scattering angles, which for vertical pointing lidars occur near sunrise/sunset. Asymmetric skylight reduction sometimes observed in experimental results is explained by the measured increase in PWV and subsequent modification of aerosol optical depth by dehydration from morning to afternoon. It was also demonstrated that the orientation of the scattering plane defining the minimum noise state does not change in multiple scattering but follows the solar azimuth angle even for high aerosol loading. Therefore, it is quite conceivable to automate this procedure simply by using solar position calculators to orient the polarization axes.

\section{Acknowledgment}

I greatly would like to express my sincere appreciation and thankful to almighty God, Allah. Then, secondly, I am grateful to Drs. S Ahmed, B Gross, and Moshary, for their support during this research at The City University of New York. This work was supported under contract from NOAA \# NA17AE1625. 


\section{References}

Ahmed, S., Y. Hassebo, et al. (2006). Examination of Reductions in Detected Skylight Background Signal Attainable in Elastic Backscatter Lidar Systems Using Polarization Selection. 23rd International Laser Radar Conference (ILRC), Nara, Japan.

Ahmed, S. A., Yasser Y. Hassebo, et al. (2006). Potential and range of application of elastic backscatter lidar systems using polarization selection to minimize detected skylight noise. SPIE, Sweden.

Ansmann, A., U. Wanginger, M. Riebesell, C. Weitkamp amd W. Michaelis (1992). "Independent measurement of extinction and backscatter profiles in cirrus clouds by using a combined Raman elastic-backscatter lidar." Appl. Opt. 33: 7113-7131.

Applications, U.S. N. O. A. "U.S. Naval Observatory Astronomical Applications, http://aa.usno.navy.mil/data/docs/AltAz.html."

Barber, P., and C.Yeh (1975). "Scattering of Electromagnetic Waves by Arbitrarily Shaped Dielectric Bodies." Appl. Opt 14: 2864-2872.

Barnaba F and a. G. Gobbi (2001). "Lidar estimation of tropospheric aerosol extinction, surface area and volume: Maritime and desert-dust cases. ." J. Geophys. Res. 106 (D3): 3005-3018.

Bills, R., C. Gardner, and C. She (1991). "Narrowband lidar technique for sodium temprature and Doppler wind observations of the upper atmosphere." Opt. Eng. 30(a): 13-21.

Charleon, R. J. E. (1995). Aeroeol forcing of climate. New York, J. Wllay.

Charlson, R. J., J. Langner, et al. (1991). "Perturbation of the northern hemisphere radiative balance by backscattering from anthropogenic sulfate aerosols." Tellus 43AB: 152163.

Charlson, R. J., S. E. Schwartz, et al. (1992). " Climate forcing by anthropogenic aerosols." Science 255: 423-430.

Deirmendjian, D. (1969). Electromagnetic Scattering on Spherical Polydispersion. New York.

Douglass L. R., M.R. Schoeberl, et al. (2000). "A composite view of ozone evolution in the 1995-1996 northern winter polar vortex developed from airborne lidar and satellite observations." J. Geophys Res. 106 (D9): 9879-9895.

Gobbi, G. P. (1998). "Polarization lidar returns from aerosols and thin clouds: a framework for the analysis." Appl. Opt. 37: 5505-5508.

Gardner, C. S., et al. (1993). " Simultaneous observations of sporadic E, Na, Fe, and Ca+ layers at Urbana, Illinois: Three case studies." J. Geophys. Res. 98: 16,865-16,873.

Gelbwachs, A. (1994). "Iron Boltzmann factor lidar: proposed new remote sensing technique for atmospheric temperature." Appl. Opt(33): 7151-7156.

Granier, C., J. P. Jegou, et al. (1989). "Iron atoms and metallic species in the Earth's upper atmosphere." Geophys. Res. Lett. 16: 243-246.

Halldorsson and a. J. Langerhoic (1978). "Geometrical form factors for the lidar function." Appl. Opt 17: 240-244.

Hamamatsu: http:/ / www.hamamatsu.com

Hansen, J. and a. L. Travis (1974). "Light Scattering in Planetary Atmospheres." Space Science Reviews 16: 527-610

Hassebo, Y., R. Agishev, et al. (2004). Optimization of Biaxial Raman Lidar receivers to the overlap factor effect" Third NOAA CREST Symposium, Hampton, VA USA. 
Hassebo, Y. Y., B. Gross, et al. (2005). Polarization discrimination technique to maximize LIDAR signal-to-noise ratio. Polarization Science and Remote Sensing II, SPIE

Hassebo, Y. Y., B. Gross, et al. (2006). "Polarization discrimination technique to maximize LIDAR signal-to-noise ratio for daylight operations." App. Opt. 45: 5521-5531.

Hassebo, Y. Y., Barry M. Gross, et al. (2005). Impact on lidar system parameters of polarization selection / tracking scheme to reduce daylight noise. Lidar Technologies, Techniques, and Measurements for Atmospheric Remote Sensing, SPIE.

Hassebo, Y. Y., Y. Zhao, et al. (2005). Multi-wavelength Lidar Measurements at the City College of New York in Support of the NOAA-NEAQS and NASA-INTEX-NA Experiments IEEE.

Heaps, W. S., J. Burris (1996). "Airborne Raman lidar." Appl. Opt 35: 7128-7137.

Heaps, W. S., J. Burris, and J. French (1997). "Lidar technique for remote measurement of temperature by use for a vibrational-rotational Raman spectroscopy." Appl. Opt 36: 9402-9405.

Jegou, J., M.Chanin, et al. (1980). "Lidar measurements of atmospheric lithium." Geophys. Res. Lett. 7: 995-998.

Jones, F. E. (1949). "Radar as an aid to the study of the atmosphere " Royal Aeronautical Society 53: 433-448.

Junge, C. (1955). "The size distribution and aging of natural aerosol as determined from electrical and optical data on the atmpsphere." J. Meteorol 12: 13-25.

Klett, J. D. (1981). "Stable analytical inversion solution for processing lidar returns." Appl. Opt. 20: 211-220.

Klett, J. D. (1985). "Lidar inversion with variable backscatter/extinction ratios" Appl. Opt. 24: 1638-1985.

Kokkinos, D. S. and S. A. Ahmed (1989). Atmospheric depolarization of lidar backscatter signals. Lasers ' 88 ' International Conference, Lake Tahoe, NV, STS Press.

Kovalev, V. and H. Moosmüller (1994). "Distortion of particulate extinction profiles measured with lidar in a two-component atmosphere." Appl. Opt. 33: 6499-6507.

Kovalev, V. and W. Eichinger (2004). Elastic Lidar, Theory, Practice, and Analysis Mathods. New Jersey, Wiley.

Liou, K. N. (2002). An Introduction to Atmospheric Radiation. California, Academic Press.

McClung, F. J. a. R. W. H. (1962). "Giant Optical Pulsations from Ruby." Appl. Phys. 33: 828829.

Measures, R. M. (1984). Laser Remote Sensing: Fundamentals and Applications. NY, Wiley.

Measures. R. M., a. G. P. (1972). "A Study of Tunable Laser Techniques for Remote Mapping of Specific Gaseous Constituents of the Atmosphere." Opto-electronics 4: 141-153.

Middleton, W. E. K., and A.F.Spilhaus (1953). Meteorological Instruments. Toronto, , University of Toronto Press.

Mie, G. (1908). Annalen der Physik 24: 376-445.

MODIS Collection 5 Aerosol Retrieval Theoretical Basis Document.

NOAA-CREST " http:/ / earth.engr.ccny.cuny.edu/noaa/wc/DailyData/."

NOAA " http://www.fsl.noaa.gov." 
Petri, K., A. Salik, and J. Coony (1982). "Variable-Wavelength Solar-Blind Raman Lidar for Remote Measurement of Atmospheric Water-Vapor Concentration and Temprature." Appl. Opt 21: 1212-1218.

Platt, C. M. R. (1977). "Lidar observation of a mixed-phase altostratus cloud." J. Appl. Meteorol. 16: 339-345.

Platt, C. M. R. (1981). Transmission and reflectivity of ice clouds by active probing. Clouds, Their Formation, Optical Properties, and Effects, San Diego, Calif., Academic.

Renaut, J., C. Pourny, and R. Capitini (1980). "Daytime Raman-LidarMeasurements of Water Vapor." Optics Letters 5: 233-235.

Rodriguez, M., R. Sauerbrey, et al. (2002). "Optics Letters." 27(772).

Roy, N., G. Roy, et al. (2004). "Measurement of the azimuthal dependence of cross-polarized lidar returns and its relation to optical depth." Appl. Opt. 43: 2777-2785.

Sassen, H. Z. K., et al. (1992). "Simulated polarization diversity lidar returns from water and precipitating mixed phase clouds." Appl. Opt. 31: 2914-2923.

Sassen, K. (1974). "Depolarization of laser light backscattered by artificial clouds." J. Appl. Meterol. 13: 923-933.

Sassen, K. (1979). "Scattering of polarized laser light by water droplet, mixed-phase and ice crystal clouds. 2. Angular depolarization and multiple scatter behavior." J. Atmos. Sci 36: 852-61.

Sassen, K. (1994). "Advanced in polarization diversity lidar for cloud remote sensing." Proc. IEEE 82: 1907-1914.

Sassen, K. and a. R. L. Petrilla (1986). "Lidar depolarization from multiple scattering in marine stratus clouds." Appl. Opt. 25: 1450- 1459.

Schotland, R. M. (1966). Some Obsevation of the vertical Profile of Water Vapor by a Laser Optical Radar. 4th Symposium on Remote Sensing of the Environment Univ. of Michigan.

Schotland, R. M., K. Sassen, et al. (1971). "Observations by lidar of linear depolarization ratios by hydrometeors." J. Appl. Meteorol 10: 1011-1017.

She, C. and a. J. Yu (1994). "Simultaneous three-frequency Na lidar measurements of radial wind and temperature in the mesopause region." Geophys. Res. Lett. 21: 1771-1774.

Spinhirne, J. D. (1991). Lidar aerosol and cloud backscatter at 0.53, 1.06 and $1.54 \mu \mathrm{m}$. presented at the 29th Aerospace Sciences Meeting, Reno, NV.

Spinhirne, J. D. (1993). "Micro pulse lidar." IEEE TRANSACTIONS ON GEOSCIENCE AND REMOTE SENSING 31: 48-54.

Stein, B., C. Wedekind, et al. (1999). "Optical classification, existence temperatures, and coexistence of different polar stratospheric cloud types." J. Geophys. Res. 104 (D19): 23983-23993.

Stephens, G. L. (1994). Remote Sensing of the Lower Atmosphere: An Introduction. New York, Oxford Univ. Press.

Takashi Fhjii and T. Fukuchi (2005). Laser Remote Sensing, Taylor and Francis Group

Velotta, R., B. Bartoli, et al. (1998). "Analysis of the receiver response in lidar measurements." Appl. Opt. 37: 6999-7007.

Welton, E., J. Campble, et al. (2001). First Annual Report: The Micro-pulse Lidar Woldwide Observational Network, Project Report

Wiscombe, W. J. (1980). "Improved Mie Scattering Algorithms." Appl. Opt 19: 1505. 
Wöste, L., C. Wedekind, et al. (1997). "Laser und Optoelektronik " 29 (5)(51).

Zuev V., V. Burlakov, et al. (1998). "Ten Years (1986-1995) of lidar observations of temporal and vertical structure of stratospheric aerosol over Siberia." J. Aerosol Sci. 29 11791187. 
REMOTE SENSING

ADVANCED TICHNIQUES AND PLATFORMS

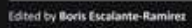

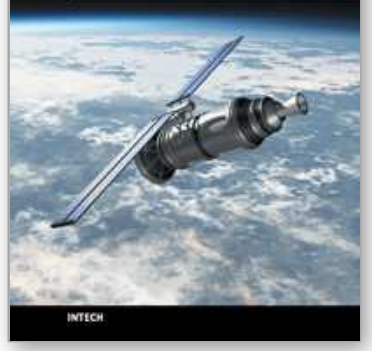

\section{Remote Sensing - Advanced Techniques and Platforms}

Edited by Dr. Boris Escalante

ISBN 978-953-51-0652-4

Hard cover, 462 pages

Publisher InTech

Published online 13, June, 2012

Published in print edition June, 2012

This dual conception of remote sensing brought us to the idea of preparing two different books; in addition to the first book which displays recent advances in remote sensing applications, this book is devoted to new techniques for data processing, sensors and platforms. We do not intend this book to cover all aspects of remote sensing techniques and platforms, since it would be an impossible task for a single volume. Instead, we have collected a number of high-quality, original and representative contributions in those areas.

\section{How to reference}

In order to correctly reference this scholarly work, feel free to copy and paste the following:

Yasser Hassebo (2012). Active Remote Sensing: Lidar SNR Improvements, Remote Sensing - Advanced Techniques and Platforms, Dr. Boris Escalante (Ed.), ISBN: 978-953-51-0652-4, InTech, Available from: http://www.intechopen.com/books/remote-sensing-advanced-techniques-and-platforms/active-remote-sensinglidar-snr-improvements

\section{INTECH}

open science | open minds

\section{InTech Europe}

University Campus STeP Ri

Slavka Krautzeka 83/A

51000 Rijeka, Croatia

Phone: +385 (51) 770447

Fax: +385 (51) 686166

www.intechopen.com

\section{InTech China}

Unit 405, Office Block, Hotel Equatorial Shanghai

No.65, Yan An Road (West), Shanghai, 200040, China

中国上海市延安西路65号上海国际贵都大饭店办公楼 405 单元

Phone: +86-21-62489820

Fax: $+86-21-62489821$ 
(C) 2012 The Author(s). Licensee IntechOpen. This is an open access article distributed under the terms of the Creative Commons Attribution 3.0 License, which permits unrestricted use, distribution, and reproduction in any medium, provided the original work is properly cited. 